\title{
Current Recommendations for Cervical Cancer Screening: Do They Render the Annual Pelvic Examination Obsolete?
}

\author{
Robert P. Kauffman Stephen J. Griffin Jon D. Lund Paul E. Tullar \\ Department of Obstetrics and Gynecology, Texas Tech University Health Sciences Center School of Medicine, \\ Amarillo, Tex., USA
}

\section{Key Words}

Cervical cytology $\cdot$ Pap smear · Guidelines • Pelvic examination $\cdot$ Human papilloma virus $\cdot$ Evidence-based medicine

\begin{abstract}
The development of a screening test for cervical dysplasia has been a major force in diminishing the worldwide incidence of invasive cervical cancer. Screening intervals recommended by professional organizations have changed over the past half century. Recognition of the human papillomavirus (HPV) as the causative agent and enhanced understanding of the natural history of HPV and cervical dysplasia in different age groups have prompted the American College of Obstetricians and Gynecologists and other professional societies to defer Pap smear screening to intervals no less than 2 years apart in women 21-29, and every 3 years in women 30 and over assuming no prior history of cervical dysplasia. Screening should start no sooner than age 21 . These recommendations more closely resemble those currently practiced in Europe and other parts of the developed world. Those who have undergone hysterectomy no longer
\end{abstract}

\begin{tabular}{ll}
\hline KARGER & $\begin{array}{l}\text { ( } 2013 \mathrm{~S} . \text { Karger AG, Basel } \\
1011-7571 / 13 / 0224-0313 \$ 38.00 / 0 \quad \text { Karger }\end{array}$ \\
E-Mail karger@karger.com & $\begin{array}{l}\text { This is an Open Access article licensed under the terms of the } \\
\text { www.karger.com/mpp }\end{array}$ \\
& $\begin{array}{l}\text { Creative Commons Attribution-NonCommercial 3.0 Un- } \\
\text { ported license (CC BY-NC) (www.karger.com/OA-license), } \\
\text { applicable to the online version of the article only. Distribu- } \\
\text { tion permitted for non-commercial purposes only. }\end{array}$
\end{tabular}

need screening unless high-grade dysplasia was present. Although the value of pelvic examination is not debated in women with symptoms referable to the female genital tract, the endorsement by several professional societies of less than annual cervical cancer screening in healthy women also begs the question of whether annual pelvic examination (speculum and/or bimanual examination) benefits asymptomatic women. Some sexually transmitted infections are amenable to self-insertion of a vaginal probe or detectable by voided urine specimen. Bimanual examination is insensitive in detecting early ovarian cancer with a high false-positive rate leading to patient anxiety, excessive diagnostic testing, and unnecessary surgical procedures. Future study should focus on the frequency in which healthy asymptomatic women should undergo pelvic examination.

Copyright $\odot 2013$ S. Karger AG, Basel

\section{Clinical Scenarios}

Should either of the following women undergo pelvic examination and cervical cancer screening?

Robert P. Kauffman, MD

Department of Obstetrics and Gynecology, TTUHSC

1400 S. Coulter Drive

Amarillo, TX 79106 (USA)

E-Mail robert.kauffman@ttuhsc.edu 
Case 1. A healthy 19-year-old university student has been sexually active for 4 months and requests oral contraceptive pills. She has mild dysmenorrhea relieved with ibuprofen and no other complaints.

Case 2. A 40-year-old woman with 3 children, married for 16 years, underwent tubal sterilization following birth of her last child. She has no complaints. She has been undergoing screening for cervical cancer every year for the past 18 years with no abnormal Pap smears recorded.

Neither of these women are candidates for cervical cancer screening at the time of presentation, and a worthy case can be made that pelvic examination could be deferred as well. However, each would benefit by a discussion of age-appropriate health-related issues. Of course, individual physician judgment remains an essential component of patient care.

In the case of the sexually active student, neither a Pap smear nor pelvic exam is necessary to start oral contraceptive pills [1]. Pap smear and speculum examination should begin no sooner than age 21 [1-5].

In fact, other than vital signs, a robust argument can be made that most teenagers do not need a physical examination at all before starting oral contraceptive pills. Sexually active women under 26 should be assessed periodically for sexually transmitted infections (STIs), primarily Chlamydia trachomatis [6, 7]. Testing can be performed by instructing the patient to self-insert a nucleic acid amplification probe into her vagina or by submitting a first-pass urine to the same technology. Both of these approaches are preferred by young patients over speculum examination $[8,9]$. Sensitivities and specificities for Neisseria gonorrhea and C. trachomatis are excellent for physician- and patient-collected vaginal specimens as well as first-pass urinary specimens. These tests perform equally well in symptomatic and asymptomatic women $[10,11]$. False positives have been reported on the urinary nucleic acid amplification platform for C. trachomatis, and patient recall for cervical or vaginal swabbing is advisable when the first-pass urine test is positive $[10,11]$.

The second case involves a healthy woman in a longterm monogamous relationship and multiple negative cervical cancer screens. Her lifetime risk of developing cervical dysplasia is very low, and hence, annual Pap smear is not cost-effective. Pelvic examination in asymptomatic women is also low yield [12]. Tubal ligation appears to decrease the lifetime risk of ovarian cancer by at least 33\% [13].

\section{Early Cervical Cancer Screening}

The Pap smear (cytological screening for premalignant and malignant cervical cells) was developed by Dr. George Papanicolaou at Cornell University in the 1940s. Both traditional slide preparations and newer liquidbased cytologies remain acceptable screening procedures in current practice [14-16]. Although 'cervical cytology' is a better descriptive term for contemporary cervical cancer screening (particularly with the wider adoption of liquid-based technologies), the more conventional term 'Pap smear' will be used in this paper.

The American Cancer Society (ACS) first advocated universal annual Pap smear screening in 1957, and the American College of Obstetricians and Gynecologists (ACOG) followed suit in 1975 after years of recommending conditional screening [17-19]. By 1980, the ACS recommendations were modified to endorse a Pap test annually beginning at age 20 or at initiation of sexual activity, but after two consecutive negative Paps, screening could be extended to every 3 years until age 65 [17]. ACOG continued to endorse annual screening for all after initial testing at the onset of sexual activity or by age 18 . This 'disagreement' prompted a lively debate [20]. Since 1980, ACOG, ACS, and US Preventive Services Task Force (USPSTF) have periodically modified guidelines for cervical cancer screening (table 1 ) [3, $5,21]$.

Early recommendations for annual cervical cancer screening appear to have been based more on tradition and convenience than science. Since cervical screening had been associated with declining rates of invasive cervical cancer, tying annual contraceptive management visits with a Pap smear seemed logical [17]. On the contrary, annual cervical cancer screening has never been the norm in most of the developed world and is not recommended by the European Commission or the World Health Organization $[4,22]$. Furthermore, annual screening has not proven more effective in preventing cervical cancer than screening performed every 3-5 years [22]. Over the past decade, consensus opinions from professional societies (particularly those in the US) have evolved away from the concept of annual or frequent Pap screening for all women. What happened?

- Discovery of chronic high-risk human papillomavirus (HPV) as the primary causative agent in cervical cancer and the ability to identify viral presence.

- Better understanding of the natural history of HPV infection and cervical dysplasia. 
Cervical cancer was the first malignancy for which widespread screening was available. Adoption of Pap smear screening remains one of the great successes of the 20th century in disease prevention. In the 60 years since the introduction of the Pap smear, the incidence of invasive cervical cancer in the US and Europe has tumbled by over $50 \%$ with a matching decrease in mortality [21,23], but the worldwide incidence remains high and continues to rise especially among indigent and medically underserved populations $[24,25]$. Eighty-six percent of all cervical cancers and $88 \%$ of all cervical cancer deaths worldwide are reported from countries with limited resources for screening and treatment [21, 25]. The highest rates of cervical cancer occur in areas with a high prevalence of HPV and human immunodeficiency virus transmission, specifically Latin America, sub-Saharan Africa, and south Asia [26]. Even in resource-rich countries with accessible health care, many women at high risk of developing cervical cancer fail to present for any health screenings much less a Pap smear or pelvic exam. Over $50 \%$ of those who develop cervical cancer have never been screened, and another 10\% more have not been screened within the previous 5 years [14, 27]. Accordingly, the larger issue public health issue at hand is getting all women screened on a regular basis [28].

\section{Human Papillomavirus}

HPV is recognized uniformly as the primary cause of cervical cancer $[1,25]$. HPV is an STI, and $50-70 \%$ of sexually active women in the US will test positive for HPV within 3 years following initiation of intercourse [29-33]. As many as $80 \%$ of women will be exposed to one or more high- or low-risk HPV types at some point during their lives [34]. Widespread HPV vaccination of adolescent boys and girls is likely to be the best weapon in preventing future cases of cervical cancer in women and HPV-related diseases in men, but some parents have been reluctant to allow vaccination of their adolescent children. Cost of the vaccine series and concerns that HPV vaccination will promote sexual activity represent the two largest barriers to vaccination in the US [35]. Given the high prevalence of HPV in young women (even in higher socioeconomic strata), withholding this vaccination would seem unwise. In resource-poor countries, the cost and distribution of HPV vaccination will be a challenge for the foreseeable future $[25,36]$.

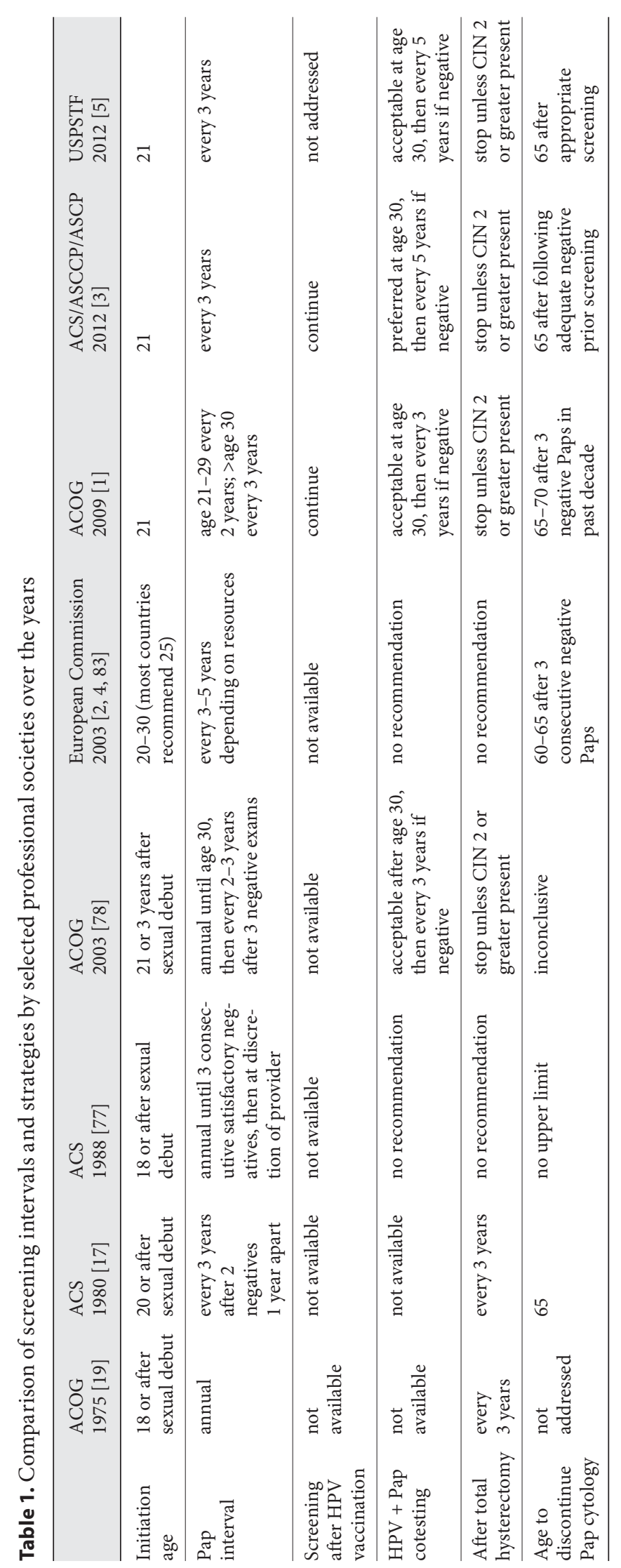

Med Princ Pract 2013;22:313-322 DOI: $10.1159 / 000346137$ 
Two HPV vaccines are currently available in the US the bivalent Cervarix (genotypes 16 and 18) and the quadrivalent Gardisil (types 6, 11, 16, and 18). Genotypes 16 and 18 account for $70-80 \%$ of all cases of invasive cervical carcinoma $[37,38]$. Genotype 45 is common in women with invasive adenocarcinoma of the cervix [38]. Despite proven effectiveness, universal vaccination is not expected to be totally eradicative since another dozen or so HPV genotypes (particularly $31,33,35,52$, and 58) carry lesser oncogenic potential $[38,39]$. Even if widespread vaccination can be implemented, it is estimated that 15-20 years will pass before a substantial reduction in cervical cancer is realized [40].

Women who have completed the three-part series of HPV immunizations should undergo Pap screening identical to those who have not been vaccinated [6]. Young women with prior cervical dysplasia or established $\mathrm{HPV}$ infection are candidates for vaccination due to high efficacy against infection with HPV strains for which they may be immunologically naïve [41].

\section{Natural History of Cervical Dysplasia and HPV Infection}

In the past, prevailing opinion held that mild dysplasia (CIN-1) eventually developed into severe dysplasia (CIN3), which ultimately evolved into invasive cervical cancer unless an intervention was performed. Sadly, this assumption has not been validated by longitudinal study. $\mathrm{CIN}-1$ is now recognized primarily as a manifestation of viral infection rather than a neoplastic lesion [42]. In the past, many women with mild cervical dysplasia were subjected to unnecessary therapeutic procedures (loop excision or conization) and were placed at risk for immediate morbidity (hemorrhage) or future obstetrical complications (cervical incompetence, preterm labor, and preterm birth) [43-46].

In the absence of a compromised immune system, most women clear the HPV from the genital tract within $8-24$ months following infection [6, 30, 31]. Young women tend to be more successful in eliminating the viral load than older women. In fact, up to $91 \%$ of young women with low-grade intraepithelial neoplasia (LSIL) on Pap smear will record a normal test at 3 years without treatment [32]. Only those with persistent high risk HPV (particularly with the more oncogenic genotypes 16 and 18) tend to develop cervical dysplasia, and the persistence of HPV tends to correlate with higher rates of advanced dysplasia found in older women [30, 38, 47]. Since women aged 25 or younger with HPV and cervical dysplasia are likely to clear these conditions spontaneously, the recommendation to hold Pap screenings until age 21 has evolved in the US although most EU countries defer screening until age 25 or later $[2,4,30,48]$.

\section{New Recommendations for Cervical Cancer Screening}

Annual Pap testing has never been established to be a cost-effective strategy [49]. Several organizations recently have modified recommendations for cervical cancer screening, including (1) ACOG [6, 14], (2) ACS/American Society for Colposcopy and Cervical Pathology (ASCCP)/ American Society for Clinical Pathology (ASCP) [3, 50], and (3) USPSTF [5, 51] (table 1). The US-based guidelines are relatively uniform with only minor differences, but in aggregate, they represent a clear departure from the concept of the 'annual Pap smear' in women without a history of cervical dysplasia. Parenthetically, these newer guidelines conform more closely to existing European Commission recommendations (table 1). Women with a history of cervical dysplasia (particularly CIN-2 or greater), infected with the human immunodeficiency virus, or who are immunosuppressed fall outside of these guidelines and will not be addressed in this review. Women who were exposed to diethylstilbestrol in utero constitute another group who should be screened annually since the lifetime risk of CIN-2 or greater is twice that of unexposed women [52].

\section{Initial Screening}

Three US-based organizations (ACOG, ACS/ASCCP/ ASCP, and USPSTF) now advise that cervical cancer screening should start no earlier than age 21 irrespective of when sexual activity was initiated [3, 5, 6, 50, 51]. In contrast, European Commission guidelines recommend initial screening between the ages of 20 and 30 with wide variations existing among countries. Women at age 20 are eligible for screening in Germany and Austria while Finland and the Netherlands defer initial screening until age 30 . Age 25 is the earliest age eligible for screening in most of Europe [2, 4].

Contrary to early Pap recommendations formulated over a generation ago, contemporary guidelines are based on sound epidemiology. Although up to $70 \%$ of young women contact HPV shortly after initiation of sexual activity, around $70 \%$ clear the infection spontaneously within 2 years [30-34]. Furthermore, most teens and 
young adults do not experience neoplastic change, and of those who do, the overwhelming majority clear dysplastic changes spontaneously. Even CIN-2 or greater tends to regress without further treatment in young women with resolution rates reported at $61-65 \%$ and $75-91 \%$ at $12-18$ months and 3 years, respectively $[32,53,54]$.

Invasive cervical cancer is rare in women less than 21 years of age. The SEER database recorded only 1-2 cases per million females between the ages of 15 and 19 [23]. Given the undeniable rarity of cervical cancer in women less than 21 and the potential morbidity and anxiety associated with diagnosis and treatment of mild dysplasia, aggressive screening, diagnostic testing, and treatment of dysplasia in this age group would seem difficult to justify [1].

There is no scientific basis to insist upon a Pap smear before initiation of hormonal contraception; however, sexually active young women should be screened for STIs $[6,7]$. Perhaps a weakness in current guidelines is the policy of screening women 21 and older who have never been sexually active. Overscreening in this select group leads to excessive healthcare expenditures and the inevitable false-positive results associated with overtesting.

\section{Screening in the 3rd Decade (Ages 21-29)}

Screening during this decade is now recommended every 2 years by ACOG and every 3 years by ACS/ASCCP/ ASCP and USPSTF $[5,14,50,51,55]$. In contrast, the European Commission recommends screening every 3-5 years $[2,4]$. Again, those with specific risk factors (human immunodeficiency virus, prior dysplasia, etc.) should follow established guidelines designed for these special populations.

\section{Screening in Women Age 30 and over}

New ACOG, ACS/ASCCP/ASCP, and USPSTF guidelines recommend screening every 3 years in women who have had consecutive negative Paps $[3,5,14,50,51]$. European Commission guidelines do not differentiate those under age 30 from older premenopausal women, continuing to recommend screening at 3- to 5-year intervals $[2,4]$. The more negative Pap screenings recorded over a lifetime, the greater likelihood of subsequent normal screens $[2,4,6]$.

High-sensitivity HPV DNA screening should be considered in this age group. In the past, HPV testing was usually limited for disposition of premenopausal women with atypical squamous cells of uncertain significance on Pap and postmenopausal women with LSIL. In the large, randomized POBASCAM trial, the addition of HPV
DNA testing to cervical cytological screening led to earlier detection of CIN-2 (and higher grade lesions) compared to cytology alone resulting in decreased progression to CIN-3 and invasive cervical cancer [56]. The recently published EUROGIN roadmap recommends addition of HPV screening every 5-8 years in addition to periodic cytological screening in women age 30-35 and older [36]. Because of the high prevalence of HPV infection in women under 30 years of age, routine HPV screening is not recommended in this age group [57]. Women age 30 and over with a negative cervical cytology and negative HPV DNA are at very low risk for development of dysplasia over the next $4-6$ years $[1,36,56,58,59]$.

\section{Menopausal Women}

The age when Pap screening can be safely discontinued is not clear. Postmenopausal women with several negative Paps are at low risk for cervical cancer, but those with new or multiple sexual partners may warrant continued screening [14]. ACOG recommends screening until age 65-70 if three negative cytologies have been obtained in the past 10 years [14]. ACS/ASCCP/ASCP, USPSTF, and European Commission guidelines recommend cessation of screening at age 65 under relatively similar conditions $[2-5,50,51]$.

It is noteworthy that a substudy of the HERS data found that Pap screening in postmenopausal women may be associated with higher false-positive results than in younger populations due to vaginal/cervical atrophy [60].

Pap smears are not a sensitive screening modality for endometrial cancer (unless endocervical involvement is present or with $>50 \%$ myometrial invasion) and should not be used for this purpose. When endometrial or uterine malignancy is suspected, direct endometrial biopsy or dilation and curettage are indicated [61-63].

\section{Hysterectomy}

Women who have undergone hysterectomy without a history of dysplasia no longer require Pap screening [3, 5, $14,50]$. Supracervical hysterectomy patients should continue screening according to age group and risk factors. Women with CIN-2 or higher at hysterectomy should continue annual screening for at least 20 years [3]. Those with CIN-1 at hysterectomy can be individualized, but many physicians would offer continued screening. Despite these recommendations, it is important to note that vaginal cancer is rare among gynecologic malignancies. The lifetime incidence of in situ and invasive disease is approximately 1 case per 200,000 women, even after hysterectomy for cervical dysplasia $[64,65]$. 
Table 2. Recommendations for routine gynecologic examinations by selected professional societies over the years

\begin{tabular}{lll}
\hline Organization & Year & Recommendation \\
\hline ACOG [19] & 1975 & annually \\
ACS [17] & 1980 & age 20-40 every 3 years, then annually after 40 \\
ACS [77] & 1988 & annually \\
ACS [55] & 2002 & no recommendation \\
USPSTF [21] & 2003 & no recommendation \\
ACOG [78] & 2003 & annually \\
ACOG [6] & 2009 & annually \\
ACOG [66] & 2012 & annually, but could be deferred after shared decision making between physician and patient \\
\hline
\end{tabular}

\section{The Pelvic Examination as Part of Well-Woman Screening}

The shift away from annual cervical cancer screening leads to another and perhaps more controversial question. Do healthy women benefit from annual pelvic examination? Although recommended by ACOG and a common practice in the US, routine annual pelvic exam in asymptomatic women is seldom practiced outside of the US $[12,22,66]$. Any screening exam in asymptomatic individuals has potential to benefit (treatment or early intervention of disease) or cause harm (false positives leading to further diagnostic testing, expense, anxiety, and unnecessary surgery) [67]. Routine pelvic examination used for the purpose of screening for gynecologic pathology would be expected to have similar risks and benefits. Within this framework, the necessity of pelvic examination as part of the annual female physical exam is worthy of reconsideration. Again, the discussion herein will be limited to the asymptomatic patient. The benefit of careful examination in women with pelvic pain, abnormal uterine bleeding, incontinence, vaginal/vulvar itching, and other gynecologic complaints is not debated. Furthermore, annual physician contact to promote a healthy lifestyle, identify and discuss medical concerns, and to enhance the patient-physician relationship remains a worthy endeavor [66].

The traditional pelvic examination is a multistep procedure consisting of (1) visualization of the external genitalia, perineum, and anus, (2) speculum-assisted inspection of the vagina and cervix, and (3) bimanual palpation of the uterus, ovaries, and adjacent structures. Rectal examination is often included. Pelvic examination remains a crucial part of the physical examination in women with symptoms attributable to gynecologic conditions. On the other hand, pelvic examination may evoke anxiety, em- barrassment, and fear that discourages or delays some women from pursuing medical services for STI screening, contraception, or even more serious diseases $[12,68]$. Unfortunately, this may translate into higher unplanned pregnancy rates, transmission of STIs, and increased risk of salpingitis (and by extension, chronic pelvic pain and tubal infertility) [69].

Pelvic examination has been touted as a prerequisite for initiation of hormonal contraception, postmenopausal hormone therapy, and gynecologic cancer screening (especially ovarian cancer), although there is a lack of scientific basis for pelvic examination for these indications $[12,14,70-74]$. Periodic screening for C. trachomatis is recommended by ACOG and the Center for Disease Control in asymptomatic sexually active women under the age of 25 , and this can be accomplished by use of a patient-inserted vaginal probe or first-pass urine with nucleic acid amplification $[6,66]$. Obviously, cervical cancer screening by Pap smear requires speculum examination, but whether the further addition of bimanual examination provides additional benefit is unknown $[12,74,75]$. One recently published study of vaginal fluid self-sampling for cytology and HPV testing in women over 50 has shown promise as a noninvasive screening strategy for premalignant conditions of the cervix [76].

Although the value of pelvic examination in women with symptoms referable to the female genital tract should not be diminished, pelvic examination in healthy, asymptomatic women has not been assessed in prospective, randomized trials. Through the years, recommendations for annual pelvic examination have been made primarily by ACOG (table 2) $[6,17,19,55,66,77,78]$. The USPSTF has not ventured an opinion on this topic [21]. A 2012 ACOG Committee Opinion paper recommends annual pelvic examination in women age 21 and older but admits that this suggestion is based on expert opinion with no evi- 
dence supporting or refuting routine pelvic examination in asymptomatic women [66]. Indeed, no evidence exists to support annual pelvic examination as a cost-effective or efficacious measure in decreasing mortality from ovarian, endometrial, vulvar, or vaginal cancer [21]. Even in 1980, the ACS recommended pelvic examination every 3 years for women between ages 20 and 40 , and then yearly after age 40 as a screen for gynecologic cancers. The reluctance to recommend annual bimanual pelvic examination for those under 40 was based on mathematical probability: 10,000 women under 40 would require examination to detect one ovarian cancer in the asymptomatic phase [17]. Perhaps in deference to the absence of evidence, the 2012 ACOG Committee Opinion concedes that 'the decision whether or not to perform complete pelvic examination at the time of periodic health assessment for the asymptomatic patient should be a shared decision between patient and her healthcare provider' [66].

Stormo et al. [79] surveyed 1,250 physicians from three specialties (ob/gyns, internists, and family physicians) concerning their utilization of pelvic examination and found that the most common indication was 'part of wellwoman examination' followed by (in order) 'ovarian cancer screening', 'screening for other gynecologic cancers', 'STI screening,' and 'as a requirement for hormonal contraception'. As discussed earlier, STI screening can be accomplished without physical examination and use of hormonal contraception does not categorically require pelvic examination [14, 74].

Even under ideal circumstances, bimanual examination has poor sensitivity to detect adnexal masses. In one prospective study ( $\mathrm{n}=140$ women), multiple examiners (faculty physicians, resident physicians, and medical students) were asked to examine women under general anesthesia prior to undergoing laparoscopy or laparotomy performed for a host of indications. All examiners were blinded to the indication for surgery. The sensitivity and positive predictive value for detecting a left adnexal mass ranged between $0.23-0.36$ and $0.50-0.69$ and for a right adnexal mass $0.15-0.28$ and $0.26-0.39$, respectively. Specificity was reasonable $(\geq 0.79)$ in all examiner groups. Those with more extensive training and experience performed no better than those without, and patient obesity noticeably affected performance [71]. In a repeat study with similar study design, the results were equally disappointing [72]. A viable screening test should have high sensitivity, specificity, and positive predictive value, and examination under general anesthesia performed poorly in two out of three of these factors. The possibility of office examination improving on the performance of pelvic exam under anesthesia for the purpose of screening for ovarian masses would seem remote.

The prevalence of ovarian cancer is low $(30-50$ per 100,000 women), which confounds safe and cost-effective screening strategies. The accuracy of pelvic examination to detect ovarian cancer is distressingly poor, and $98 \%$ of positive screenings for suspected ovarian malignancies by pelvic examination are false positive $[79,80]$. Routine serum CA-125 and pelvic ultrasound failed to show significant value in diminishing ovarian cancer mortality over 'usual care' in the randomized, controlled, and adequately powered Prostate, Lung, Colorectal, and Ovarian Cancer Screening Trial [81]. Consequently, a situation where routine pelvic examination alone for the purpose of screening for ovarian cancer would benefit symptomfree women is difficult to imagine. In fact, considerable evidence indicates that routine bimanual examination does not lead to earlier diagnosis of ovarian cancer compared to those who do not receive it $[12,71,73]$. The 'postmenopausal palpable ovary syndrome', based on a case series of only 3 patients, was popularized in a 1971 editorial. The authors of that commentary did not disclose how many women required examination to find 3 cases of postmenopausal palpable ovary syndrome and ovarian cancer, how many women with postmenopausal palpable ovary syndrome did not have ovarian cancer at surgery (hence, unnecessary surgery), or whether the 'earlier' discovery of ovarian enlargement improved quality of life or survival [82]. Small case series are best used to formulate hypotheses that should be tested by formal clinical investigation. Overscreening leads to excessive medical procedures and the harm associated with them. In the PCLO trial, $15 \%$ of women who underwent surgery for falsepositive ovarian cancer screenings experienced a major surgical complication [81].

\section{Summary and Topics for Future Study}

Performance of cervical cytological screening as part of a routine annual examination for healthy, nonimmunosuppressed women without a history of cervical dysplasia is not supported by current science. Cervical cancer screening has been responsible in large measure for declining cervical cancer rates in the developed world, but with the identification of HPV as the causative agent and epidemiologic studies verifying the natural history of HPV and dysplasia, women should be reassured that screening intervals can be safely extended beyond 1 year. The majority of women who develop cervical cancer have 
never been screened, and therein lies the greatest challenge. HPV screening in women over 30 may be offered as an adjunct test with the potential to extend screening intervals beyond 3 years. Finally, HPV vaccination holds real potential to relegate cervical cancer to the same fate as rubella, rubeola, smallpox, and other infectious diseases, but this goal will not be realized for at least another generation, even with widespread coverage.

Women, as a whole, dislike speculum and bimanual examinations [12]. Considerable knowledge can be attained from examination of selected patients, particularly those with symptoms referable to the female genital tract. Annual pelvic examination has not been shown to decrease mortality from ovarian, endometrial, vulvar, or vaginal cancer. In light of the recommendations from professional organizations against annual screening for cervical cancer in healthy women, the following questions should be addressed:

- How often should asymptomatic women undergo bimanual examination?

- Does speculum examination for Pap smear collection also mandate bimanual examination in asymptomatic women?

- What constitutes a proper 'well-woman visit' at different ages?

Recommendations for routine screening are constantly in transition and evolution. A prospective, systematic study of the risk and benefits of routine or annual pelvic examination in asymptomatic women is overdue. If a net benefit can be demonstrated, physicians and patients can be comforted. If not, the practice of 'annual pelvic exam' should be eliminated.

\section{References}

1 ACOG committee opinion No. 431: Routine pelvic examination and cervical cytology screening. Obstet Gynecol 2009;113:11901193.

2 International Agency for Research on Cancer: IARC Handbooks of Cancer Prevention. Lyon, IARC Press, vol 10: Cervix Cancer Screening, 2005.

-3 Saslow D, Solomon D, Lawson HW, Killackey M, Kulasingam SL, Cain JM, Garcia FA, Moriarty A, et al: American Cancer Society, American Society for Colposcopy and Cervical Pathology, and American Society for Clinical Pathology screening guidelines for the prevention and early detection of cervical cancer. CA Cancer J Clin 2012;62:147172.

4 Arbyn M, Anttila A, Jordan J, Ronco G, Schenck U, Segnan N, Wiener H, et al: European Guidelines for Quality Assurance in Cervical Cancer Screening. Second edition - summary document. Ann Oncol 2010;21: 448-458.

5 Moyer V, US Preventive Services Task Force: Screening for cervical cancer: US Preventive Services Task Force recommendation statement. Ann Intern Med 2012; 156:880-891.

$\checkmark 6$ ACOG Committee Opinion No. 436: evaluation and management of abnormal cervical cytology and histology in adolescents. Obstet Gynecol 2009;113:1422-1425.

$\checkmark 7$ Ogbechie OA, Hacker MR, Dodge LE, Patil MM, Ricciotti HA: Confusion regarding cervical cancer screening and chlamydia screening among sexually active young women. Sex Transm Infect 2012;88:35-37.
8 Chernesky M, Hook EW III, Martin DH: Women find it easier and prefer to collect their own vaginal swabs to diagnose Chlamydia trachomatis or Neisseria gonorrhoeae infections. Sex Transm Dis 2005;32:729733.

-9 Schachter J, Chernesky M, Willis D: Vaginal swabs are the specimens of choice when screening for Chlamydia trachomatis and Neisseria gonorrhoeae: results from a multicenter evaluation of the APTIMA assays for both infections. Sex Transm Dis 2005;32: 725-728.

10 Gaydos C, Cartwright CP, Colaninno P, Welsch J, Holden J, Ho S, Webb EM: Performance of the Abbott RealTime CT/NG for detection of Chlamydia trachomatis and Neisseria gonorrhoeae. J Clin Microbiol 2010;48:3236-3243.

11 Shafer MA, Moncada J, Boyer CB, Betsinger K, Flinn SD, Schachter J: Comparing firstvoid urine specimens, self-collected vaginal swabs, and endocervical specimens to detect Chlamydia trachomatis and Neisseria gonorrhoeae by a nucleic acid amplification test. J Clin Microbiol 2003;41:4395-4399.

12 Westhoff C, Jones H, Guiahi M: Do new guidelines and technology make the routine pelvic examination obsolete? J Womens Health 2011;20:5-10.

13 Cibula D, Widschwendter M, Májek O, Dusek L: Tubal ligation and the risk of ovarian cancer: review and meta-analysis. Hum Reprod Update 2011;17:55-67.

14 ACOG Practice Bulletin No. 109: Cervical cytology screening. Obstet Gynecol 2009; 114:1409-1420.
15 Abulafia O, Pezzullo JC, Sherer DM: Performance of ThinPrep liquid-based cervical cytology in comparison with conventionally prepared Papanicolaou smears: a quantitative survey. Gynecol Oncol 2003;90:137-144.

$>16$ Ronco G, Cuzick J, Pierotti P, Cariaggi MP, Palma P, Naldoni C, Ghiringhello B: Accuracy of liquid based versus conventional $c y-$ tology: overall results of new technologies for cervical cancer screening randomized controlled trial. BMJ 2007;335:28.

17 American Cancer Society: Guidelines for the cancer related checkup: recommendations and rationale (Cervical Cancer). CA Cancer J Clin 1980;30:215-223.

18 American College of Obstetricians and Gynecologists: Manual of Standards in Obstetric-Gynecologic Practice, ed 2. Chicago, ACOG, 1965.

19 American College of Obstetricians and Gynecologists. ACOG Technical Bulletin No. 29: The frequency with which a cervical-vaginal cytologic examination should be performed in gynecologic practice. Chicago, ACOG, 1975.

20 Pap smear controversy pits cancer society vs ob-gyns. Hosp Pract (Hosp Ed) 1981;16:16, 21, 24, 29.

21 Waxman AG: Guidelines for cervical cancer screening: history and scientific rationale. Clin Obstet Gynecol 2005;48:77-97.

22 Habbema D, deKok I, Brown M: Cervical cancer screening in the United States and the Netherlands: a tale of two countries. Milbank Q 2012;90:5-37.

23 Howlander R, Noone AM, Krapcho M, Neyman N, Aminou R, Waldron W, Altekruse S, Kosary CL, et al: SEER Cancer Statistics Review, 1975-2008. Bethesda, National Cancer Institute, 2010. 
-24 Forouzanfar M, Foreman K, Delossantos A, Lozano R, Lopez A, Murray C, Naghavi M: Breast and cervical cancer in 187 countries between 1980 and 2010: a systematic analysis. Lancet 2011;378:1461-1484.

25 Arbyn M, Castellsague X, de Sanjose S, Bruni L, Saraiya M, Bray F, Ferlay J: Worldside burden of cervical cancer in 2008. Ann Oncol 2011;22:2675-2686.

26 Jemal A, Bray F, Center M, Ferlay J, Ward E, Forman D: Global cancer statistics. CA Cancer J Clin 2011;61:69-90.

-27 Sawaya GF, Grimes DA: New technologies in cervical cytology screening: a word of caution. Obstet Gynecol 1999;94:307-310.

-28 Sankaranarayanan R, Thara S, Esmy P, Basu $P$ : Cervical cancer: screening and therapeutic perspectives. Med Princ Pract 2008; 17 : 354-364.

29 Moscicki AB: Cervical cytology testing in teens. Curr Opin Obstet Gynecol 2005;17: 471-475.

- 30 Ho GY, Bierman R, Beardsley L, Chang CJ, Burk RD: Natural history of cervicovaginal papillomavirus infection in young women. N Engl J Med 1998;338:423-428.

- 31 Insinga R, Dasbach E, Elbasha E, Liaw K, Barr E: Incidence and duration of cervical human papillomavirus $6,11,16$, and 18 infections in young women: an evaluation from multiple analytic perspectives. Cancer Epidemiol Biomarkers Prev 2007;16:709715.

32 Moscicki AB, Shiboski S, Hills N, Powell K, Jay N, Hanson E, et al: Regression of lowgrade squamous intra-epithelial neoplasia in young women. Lancet 2004;364:1678-1683.

-33 Moscicki AB, Shiboski S, Broerling J, Powell K, Clayton L, Jay N, Darragh T, et al: The natural history of human papillomavirus infection as measure by repeated DNA testing in adolescent and young women. J Pediatr 1998; 132:277-284

34 Koutsky L: Epidemiology of genital human papillomavirus infection. Am J Med 1997; 102:3-8.

35 Brewer N, Fazekas K: Predictors of HPV vaccine acceptability: a theory-informed, systematic review. Prev Med 2007;45:107-114.

- 36 Arbyn M, de Sanjose S, Saraiya M, Sideri M, Palefsky J, Lacey CJ, Gillison ML: EUROGIN 2011 roadmap on prevention and treatment of HPV-related disease. Int J Cancer 2012; 131:1969-1982.

37 Smith J, Melendy A, Rana R, Pimenta J: Agespecific prevalence of infection with human papillomavirus in females: a global review. J Adolesc Health 2008;43:S5-S25.

38 de Sanjose S, Quint WG, Alemany L, Geraets D, Klaustermeier J, Lloveras B, Tous S, Felix A, et al: Human papillomavirus genotype attribution in invasive cervical cancer: a retrospective cross-sectional worldwide study. Lancet Oncol 2010;11:1048-1056.
Schiffman M, Wentzensen N, Wacholder S, Kinney W, Gage J, Castle PE: Human papillomavirus testing in the prevention of cervical cancer. J Natl Cancer Inst 2011;103:368383.

40 Wright $\mathrm{T}$, Van Damme P, Schmitt H, Meheus A: HPV vaccine in industrialized countries. Vaccine 2006;24:122-131.

41 Garland SM, Smith J: Human papillomavirus vaccines: current status and future prospects. Drugs 2010;70:1079-1098.

42 Arbyn M, Martin-Hirsch P, Buntinx F, Van RM, Paraskevaidis E, Dillner J: Triage of women with equivocal or low-grade cervical cytology results: a meta-analysis of the HPV test positivity rate. J Cell Mol Med 2009;13: 648-659.

-43 Kyrgiou M, Koliopoulos G, Martin-Hirsch P, Arbyn M, Prendiville W, Paraskevaidis E: Obstetric outcomes after conservative treatment for intraepithelial or early invasive cervical lesions: systematic review and metaanalysis. Lancet 2006;367:489-498.

44 Noehr B, Jensen A, Frederiksen K, Tabor A, Kjaer SK: Loop electrosurgical excision of the cervix and subsequent risk for spontaneous preterm delivery: a population based study of singleton deliveries during a 9 -year period. Am J Obstet Gynecol 2009;201: 33.e1-e6.

45 Arbyn M, Kyrgiou M, Raifu A, Koliopoulos G, Martin-Hirsch P, Prendiville W, Paraskevaidis E: Perinatal mortality and other severe adverse pregnancy outcomes associated with treatment of cervical intraepithelial neoplasia: meta-analysis. BMJ 2008;337: a1284.

46 Bruinsma F, Quinn MA: The risk of preterm birth following treatment for precancerous changes in the cervix: a systematic review and meta-analysis. BJOG 2011;118:10311041.

47 Moscicki AB, Ma Y, Wibbelsman C, Darraugh T, Powers A, Farhat S, Shiboski S: Rate of and risks for regression of cervical intraepithelial neoplasia 2 in adolescents and young women. Obstet Gynecol 2010;116: 1373-1380.

48 Brown D, Shaw M, Qadadri B, Neptune N, Vargas $\mathrm{M}, \mathrm{Tu} \mathrm{W}$, et al: A longitudinal study of genital human papillomavirus infection in a cohort of closely followed adolescent women. J Infect Dis 2005;191:182-192.

- 49 Kulasingam SL, Rajan R, St PY, Atwood CV, Myers ER, Franco EL: Human papillomavirus testing with Pap triage for cervical cancer prevention in Canada: a cost-effectiveness analysis. BMC Med 2009;7:69.

50 Feldman S: Making sense of the new cervical-cancer screening guidelines. N Engl J Med 2011;365:2145-2147.

51 Vesco K, Whitlock EP, Eder M, Lin J, Burda B, Senger C, Holmes R, Zuber S: Screening for Cervical Cancer: a Systematic Evidence Review for the US Preventative Services Task Force. Rockville, Agency for Healthcare Research and Quality (US), 2011.
52 Hoover R, Hyer M, Pfeiffer R, Adam E, Bond B, Cheville A, Colton T: Adverse health outcomes in women exposed in utero to diethylstilbestrol. N Engl J Med 2011;365:1304-1314.

53 Moore K, Cofer A, Elliott L, Lanneau G, Walker J, Gold MA: Adolescent cervical dysplasia: histologic evaluation, treatment, and outcomes. Am J Obstet Gynecol 2007;197: 141.e1-e6.

54 Fuchs K, Weitzen S, Wu L, Phipps M, Boardman L: Management of cervical intraepithelial neoplasia 2 in adolescent and young women. J Pediatr Adolesc Gynecol 2007;20: 269-274.

55 Saslow D, Runowicz C, Solomon D: American Cancer Society guideline for the early detection of cervical neoplasia and cancer. CA Cancer J Clin 2002;52:342-362.

-56 Rijkaart DC, Berkhof J, Rozendaal L, van Kemenade FJ, Heideman DA, Kenter G, Cuzick J, et al: Human papillomavirus testing for the detection of high-grade intraepithelial neoplasia and cancer: final results of the POBASCAM randomized controlled trial. Lancet Oncol 2012;13:78-88.

57 Lee J, Berkowitz Z, Saraiya M: Low-risk human papillomavirus testing and other nonrecommended human papillomavirus testing practices among U.S. health care providers. Obstet Gynecol 2011;118:4-13.

58 Cuzick J, Arbyn M, Sankaranarayanan R, Tsu V, Ronco G, Mayrand MH, Dillner J, Meijer CJ: Overview of human papillomavirus-based and other novel options for cervical cancer screening in developed and developing countries. Vaccine 2008;26 (suppl 10):K29-K41.

59 Bulkmans NW, Berkhof J, Rozendaal L: Human papillomavirus DNA testing for the detection of cervical intraepithelial neoplasia grade 3 and cancer: 5 -year follow-up of a randomized controlled implementation trial. Lancet 2007;370:1764-1772.

60 Sawaya GF, Grady D, Kerlikowske K, Valleur J, Barnabei V, Bass L, et al: The positive predictive value of cervical smears in previously screened postmenpausal women: the Heart and Estrogen/Progestin Replacement Study (HERS). Ann Intern Med 2000;133:942-950.

61 Frable WJ: Screening for endometrial cancer? Cancer Cytopathol 2008;114:219-221.

62 Clark T, Mann C, Shah N, Khan K, Gupta J: Accuracy of outpatient endometrial biopsy in the diagnosis of endometrial cancer: a systematic quantitative review. BJOG 2002;109: 313-321.

63 Zhou J, Tomashefski J, Khiyami A: ThinPrep Pap tests in patients with endometrial cancer: a histo-cytological correlation. Diagn Cytopathol 2007;35:448-453.

64 Watson M, Saraiya M, Wu X: Update of HPV-associated female genital cancer in the United States, 1999-2004. J Womens Health (Larchmt) 2009;18:1731-1718. 
65 Wu X, Matanoski G, Chen V, Saraiya M, Coughlin S, King JB, Tao XG: Descriptive epidemiology of vaginal cancer incidence and survival by race, ethnicity, and age in the United States. Cancer 2008;113:2873-2782.

66 Committee on Gynecologic Practice: Committee opinion No. 534: well-woman visit. Obstet Gynecol 2012;120:421-424.

67 Woolf S, Harris R: The harms of screening: new attention to an old concern. JAMA 2012; 307:565-566.

68 Millstein SG, Adler NE, Irvin C: Sources of anxiety about pelvic examinations among adolescent females. J Adolesc Health Care 1984;5:105-111.

69 Workowski K, Berman S: Sexually transmitted diseases guidelines, 2006. MMWR Recomm Rep 2006;55(RR-11):1-94.

70 World Health Organization Department of Reproductive Health and Research: Improving Access to Quality Care in Family Planning: Medical Eligibility Criteria for Contraceptive Use. Geneva, WHO, 2000.

71 Padilla L, Radosevich D, Milad M: Accuracy of the pelvic examination in detecting adnexal masses. Obstet Gynecol 2000;96:593598.
2 Padilla L, Radosevich D, Milad M: Limitations of the pelvic examination for evaluation of the female organs. Int J Gynaecol Obstet 2005;88:84-88.

73 Bass K, Westhoff C, Bush T: Ovarian cancer: epidemiologic and clinical perspectives and the feasibility of screening. Menopause 1995; 2:145-158.

74 Stewart F, Harper C, Ellertson C, Grimes D, Sawaya GF, Trussell J: Clinical breast and pelvic examinations requirements for hormonal contraception: current practice vs evidence. JAMA 2001;285:2232-2239.

75 Schachter J, Shafer MA, Young M, Ott M: Routine pelvic examinations in asymptomatic young women. N Engl J Med 1996;335: $1847-1848$.

76 Lindell M, Sanner K, Wikstrom I, Wilander E: Self-sampling of vaginal fluid and highrisk human papillomavirus testing in women aged 50 years or older not attending Papanicolaou smear screening. BJOG 2012;119: 245-248.

77 Fink D: Change in American Cancer Society Checkup Guidelines for detection of cervical cancer. CA Cancer J Clin 1988;38:127128.
78 ACOG Practice Bulletin: clinical management guidelines for obstetrician-gynecologists. Number 45, August 2003. Cervical cytology screening (replaces committee opinion 152, March 1995). Obstet Gynecol 2003; 102:417-427.

79 Stormo A, Hawkins N, Cooper C, Saraiya M: The pelvic examination as a screening tool: practices of US physicians. Arch Intern Med 2011;171:2053-2054.

80 US Preventative Services Task Force: Screening for ovarian cancer: recommendation statement. Ann Fam Med 2004;2: 260-262.

81 Buys S, Partridge E, Black A: Effect of screening on ovarian cancer mortality: the Prostate, Lung, Colorectal and Ovarian (PLCO) Cancer Screening Randomized Controlled Trial. JAMA 2011;305:2295-2303.

82 Barber H, Graber E: The PMPO syndrome (postmenopausal palpable ovary syndrome). Obstet Gynecol 1971;38:921-923.

83 Council of the European Union: Council recommendation of 2 December 2003 on cancer screening (2003/878/EC). Off J Eur Union 2003;878:34-38. 